\title{
Pin-site epidural hematoma: A catastrophic complication of cranial fixation in a child
}

\author{
Prasad Krishnan, Soumen Kanti Kumar, Rajaraman Kartikueyan, Sachinkumar Maheshbhai Patel \\ Department of Neurosurgery, National Neurosciences Centre, Kolkata, West Bengal, India
}

\section{ABSTRACT}

Cranial fixation with pins is a routine adjunct in neurosurgery and is usually considered safe. A rarely reported complication is skull fracture at the pin site and consequent epidural hematoma. Usually, these are picked up only postoperatively and rarely, intraoperatively if there is unexplained "brain bulge" in which case the operation should be terminated and urgent imaging has to be done. We describe such a complication that occurred while operating on a 12-year-old child with a posterior fossa tumor and review the available literature dealing with such events.

Key words: Cranial fixation, depressed skull fracture, extradural hematoma, pin-site complications

\section{Introduction}

Head immobilization during cranial surgeries by devices using pin fixation is a common neurosurgical practice. ${ }^{[1-3]}$ Scalp vessel injury, air embolism, pneumocephalus, pin-site infection, shunt tube damage, parenchymal injury, and skull fracture with epidural hematoma are all reported as complications of the same..$^{[3-5]}$ Potentially, catastrophic, pin-site hematoma has been reported as having an incidence of $<0.65 \%$ (five patients in a series of 766 cases by Vitali and Steinbok $\left.{ }^{[2]}\right)$.

\section{Case Report}

A 12-year-old girl presented with holocranial headache, blurring of vision, vomiting, and ataxia of gait of 3 months duration. Magnetic resonance imaging of brain revealed a $4^{\text {th }}$ ventricular mass of mixed intensity on T1 and T2 sequences with solid

\section{Address for correspondence:}

Dr. Prasad Krishnan, Department of Neurosurgery, National Neurosciences Centre, $2^{\text {nd }}$ Floor, Peerless Hospital Campus, 360, Panchasayar, Garia, Kolkata - 700 094, West Bengal, India.

E-mail: prasad.krishnan@rediffmail.com

\begin{tabular}{|l|l|}
\hline \multicolumn{2}{|c|}{ Access this article online } \\
\hline Quick Response Code: & Website: \\
\hline & www.ruralneuropractice.com \\
\cline { 1 - 2 } & \\
\hline & \\
\hline
\end{tabular}

and cystic components enhancing nonuniformly on contrast, with hydrocephalus and periventricular lucency [Figure 1]. The patient underwent suboccipital craniectomy in the prone position after her head was stabilized with pins on a three pin fixator. Prior to opening of the dura, the ventricle was tapped through a right parietal burr hole and some cerebrospinal fluid (CSF) was let out. A telovelar approach was attempted, but during the course of the surgery, there was inadequate cerebellar relaxation, and hence, a transvermian approach was done. Gross total tumor resection was achieved microscopically and the $4^{\text {th }}$ ventricular floor was visible, but even after this, the cerebellum was bulging through the craniotomy margins. There were no obvious retraction injuries on the cerebellar surface. The ventricular drain was completely opened in an endeavor to slacken the cerebellum for closure, but it resulted in further herniation of posterior fossa structures. C1 and C2 laminectomy was done, and muscle and skin were closed with no attempt at dural closure. When the patient was turned around, both her pupils were fixed and dilated. The skull under the pin site at the left temporal region was found to be depressed, but there was no active bleeding. An urgent computed

This is an open access article distributed under the terms of the Creative Commons Attribution-NonCommercial-ShareAlike 3.0 License, which allows others to remix, tweak, and build upon the work non-commercially, as long as the author is credited and the new creations are licensed under the identical terms.

For reprints contact: reprints@medknow.com

How to cite this article: Krishnan P, Kumar SK, Kartikueyan R, Patel SM. Pin-site epidural hematoma: A catastrophic complication of cranial fixation in a child. J Neurosci Rural Pract 2016;7:286-9. 


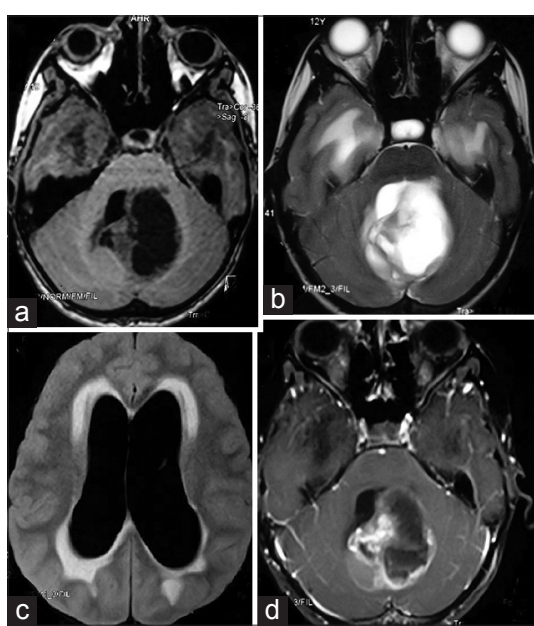

Figure 1: Axial magnetic resonance images of the brain showing ( $a$ and $b$ ) mixed intensity partly solid and partly cystic intra-axial midline posterior fossa tumor; (c) hydrocephalus with periventricular lucency on fluid attenuation inversion recovery images; and (d) heterogeneous enhancement of the lesion on contrast

tomography (CT) scan revealed a very large left-sided extradural hematoma with midline shift and effaced cisterns. The cerebellum was bulging out of the craniectomy site, but there was no cerebellar hematoma [Figure 2]. The patient was taken back to the operating room, the left temporoparietal craniotomy was done, extradural hematoma was evacuated, and depressed fracture fragment was removed. The patient was intubated and ventilated. After 3 days, her pupil size normalized. She underwent a tracheostomy and over the next 2 months, she had multiple episodes of respiratory and urinary tract infections. She developed a large posterior fossa pseudomeningocele, also had an episode of meningitis, following which she developed hydrocephalus [Figure 3]. She underwent right ventriculoperitoneal shunt. Over time, she had slow neurological improvement, and at discharge 3 months following surgery, she was verbalizing, accepting orally, was continent, ambulant with support of residual ataxia, and cerebellar signs.

\section{Discussion}

A review of literature showing the patient characteristics, pathology for which the surgery was done, and time when this complication was detected of previously reported cases ${ }^{[1-14]}$ is summarized in Table 1 . The majority of such cases, like in ours, occurred in children with posterior fossa tumors. ${ }^{[1-3,7]}$ However, this complication has been reported even in adults ${ }^{[4,13]}$ and also following surgery for supratentorial ${ }^{[1,5,11-14]}$ and cervical spinal ${ }^{[6]}$ pathology.

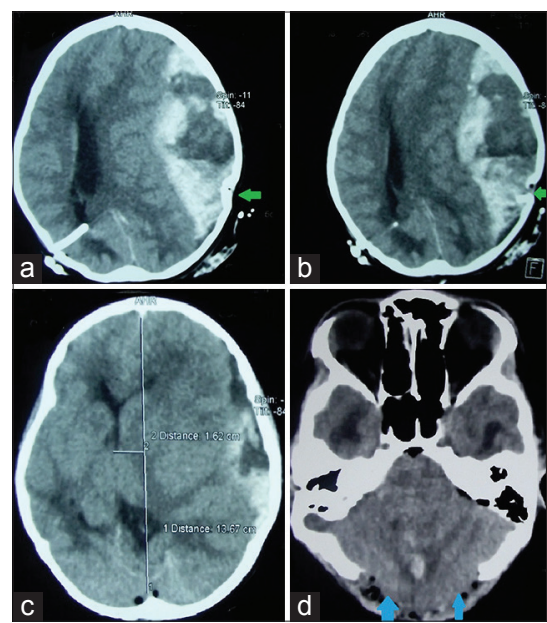

Figure 2: Immediate postoperative computed tomography scan showing ( $a$ and $b$ ) large hyperacute extradural hematoma on the left side with depressed fracture of the parietal bone driven inward (green arrows) and an external ventricular drain placed on the right side; (c) midline shift of $1.62 \mathrm{~cm}$ with effaced cisterns; and (d) cerebellum bulging out through the craniotomy defect (blue arrows) with small amount of operative site bleed

Several authors hold that preexisting hydrocephalus, as in this case, may contribute to thinning of the skull, making it fracture easily on pin pressure ${ }^{[4-7]}$ and have advised scrutiny of calvarial thickness preoperatively to reduce this complication. ${ }^{[5]}$ Although it has been mentioned that "there is no safe area for pin positioning in the pediatric skull," ${ }^{[7]}$ some state that it is important to avoid pin placement in the thin squamous part of the temporal bone. ${ }^{[3]}$ The source of hematoma is bleeding either from the margins of the fracture or injured branches of the middle meningeal artery. In our case too, the bone was fractured and driven in, but no obvious source of bleeding was encountered. The external ventricular drain, in our case, by collapsing the brain probably prevented any natural tamponade that might have otherwise occurred.

Berry et al. ${ }^{[15]}$ surveying practices among neurosurgeons treating pediatric patients notes that there are no clear-cut guidelines for the application of cranial fixation using pins in pediatric patients despite significant complications that may arise from these devices. Pin fixation is generally contraindicated in children below the age of three, ${ }^{[2]}$ and the Integra LifeScience Corporation (makers of the Mayfield Skull Clamp) states that skull pins are not recommended for use in children $<5$ years of age $\mathrm{e}^{[7]}$ and suggests that "child pins" can be used in children above this age. However, as our experience shows, even this may not be a failsafe technique. Other authors have recommended measures such as avoidance of pushing the pins, decreased clamp pressure, steering clear of 

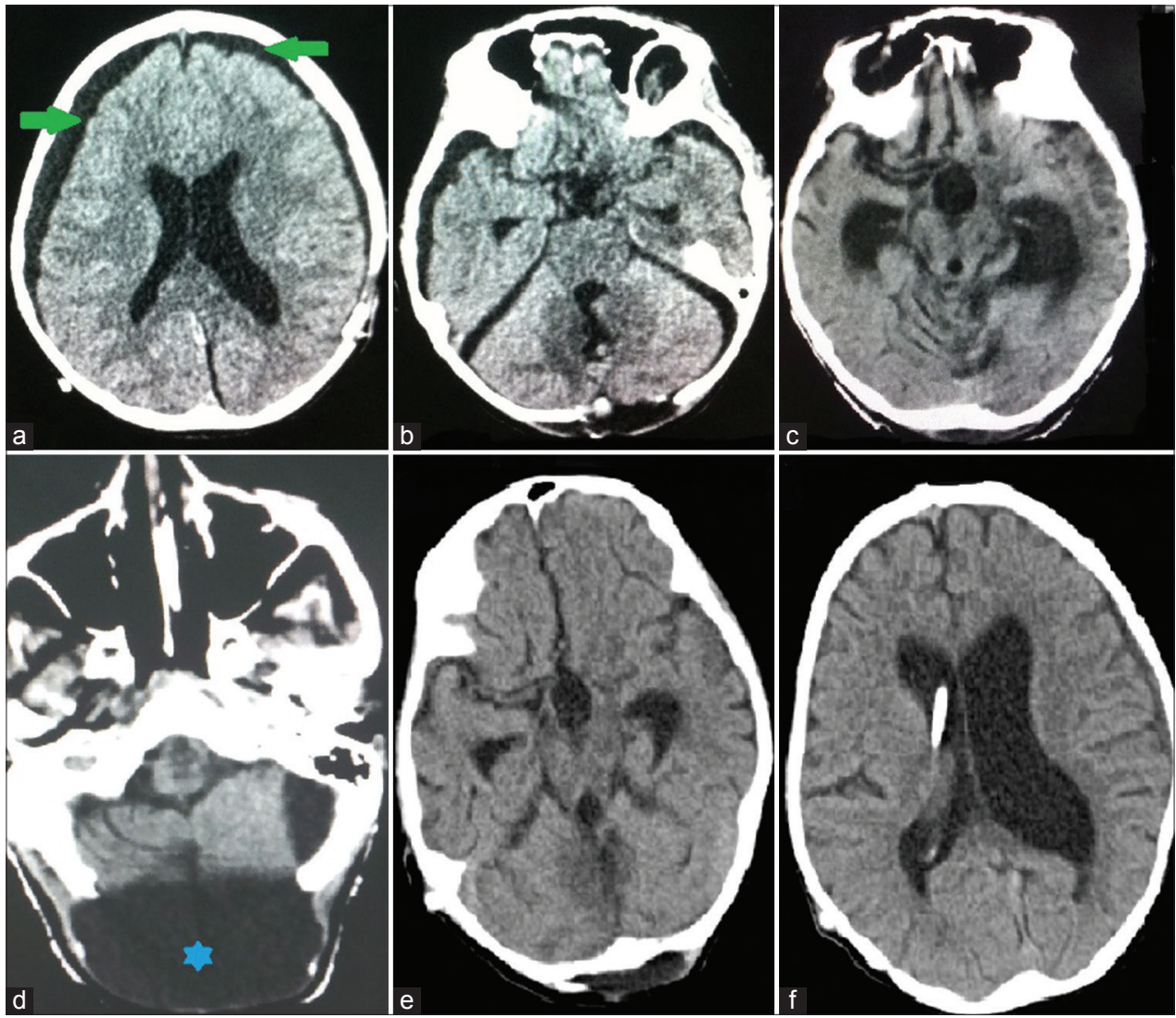

Figure 3: Axial computed tomography cuts 2 weeks after surgery (a and b) showing no residual clot, collapsed ventricles and bilateral subdural hygromas (green arrows); 6 weeks after surgery showing (c) dilated lateral and third ventricles, and (d) large occipitocervical pseudomeningocele (blue star); and 6 weeks after ventriculoperitoneal shunt and prior to discharge (e and f) showing regression of ventricular size and shunt tube in situ

pin placement in the temporal region, use of conic pins, and use of an intermediary piece and pressure adjusting springs in the clamp $p^{[3,4,7,8]}$ to prevent this occurrence.

Intraoperatively, we had noted that the cerebellum was bulging, but we tried to rectify this by draining more CSF since we did not suspect a supratentorial extradural hematoma. Other reports in literature too have described encountering the unexplained fullness of the brain resulting from this event. ${ }^{[3,4]}$ In one case, surgery was abandoned midway ${ }^{[14]}$ to get imaging done. However, in most of the cases, the hematoma was discovered either following CT scan done immediately after surgery ${ }^{[2-4,7]}$ (one exception being a case in Vitali and Steinbok's series ${ }^{[2]}$ where it was detected at the time of pin application) or later when the patient showed signs of neurological deterioration. . $^{[5,69-11,13]}$ In light of our experience, we feel that if other factors such as retraction injury and increased airway pressure can be ruled out, it would be wiser to get a scan done intraoperatively after closing the wound temporarily which would help to detect hematoma early and prevent tentorial herniation. Our delay in doing the same was contributory for the extremely protracted and stormy course of the patient.
Although our patient had a late detection (at the end of surgery, $6 \mathrm{~h}$ after onset of pin application) and had bilateral papillary dilatation, the eventual result after hematoma evacuation was gratifying. Other authors have also reported detecting this complication after anisocoria and have had equally good results. ${ }^{[7]}$ As extradural hematomas usually have a good outcome, there should be no hesitation in subjecting the patient to immediate re-surgery on detecting this event.

\section{Conclusion}

Surgeries in the posterior fossa in children can be done after placing the head in a horseshoe head rest, but as these can cause pressure sores during prolonged surgeries and since immobilization is not rigid, pin fixation devices will continue to remain the mainstay of cranial fixation in a vast majority of children. Careful pin application, under optimal pressure, in an appropriate location, with prior knowledge of calvarial thinning, early imaging in the setting of unexpected intraoperative brain herniation, and urgent surgery even in the presence of papillary dilatation will help to prevent and treat this mishap. 
Table 1: The patient characteristics, pathology for which surgery was performed, and time of detection of pin-site epidural hematoma reported by various authors in literature

\begin{tabular}{|c|c|c|c|}
\hline Author (year) & $\begin{array}{l}\text { Patient } \\
\text { characteristics }\end{array}$ & $\begin{array}{l}\text { Pathology for which surgery was } \\
\text { performed }\end{array}$ & Time of detection \\
\hline \multirow[t]{2}{*}{ Lee et al. (1994) $)^{[1]}$} & $\begin{array}{l}5 \text { children (aged } \\
2 \text { years } 7 \text { months to } \\
6 \text { and } 1 / 2 \text { years) }\end{array}$ & $\begin{array}{l}2 \text { brain stem gliomas, } 2 \text { hypothalamic } \\
\text { gliomas, and } 1 \text { medulloblastoma }\end{array}$ & NA \\
\hline & 3 males and 2 females & & \\
\hline \multirow[t]{2}{*}{ Medina et al. (1997) ${ }^{[14]}$} & 13/male & Supratentorial cystic lesion & $\begin{array}{l}\text { Intraoperatively due to cerebral } \\
\text { herniation }\end{array}$ \\
\hline & & & Operation suspended \\
\hline Erbayraktar et al. (2001) ${ }^{[12]}$ & 23/male & Pituitary adenoma & Intraoperatively \\
\hline Sade and Mohr (2005) ${ }^{[5]}$ & 24/male & Left frontoparietal meningioma & $6 \mathrm{~h}$ after surgery \\
\hline Yan $(2007)^{[9]}$ & 15/male & $\begin{array}{l}\text { Fourth ventricular choroid plexus } \\
\text { papilloma with hydrocephalus }\end{array}$ & $6 \mathrm{~h}$ after surgery \\
\hline Tang et al. $(2007)^{[10]}$ & $15 /$ male & Vermian medulloblastoma & $7 \mathrm{~h}$ postoperatively \\
\hline Vitali and Steinbok (2008) $)^{[2]}$ & $\begin{array}{l}5 \text { children (aged } \\
2 \text { years } 7 \text { months to } \\
6 \text { and } 1 / 2 \text { years) }\end{array}$ & $\begin{array}{l}\text { All posterior fossa tumors - } 2 \\
\text { medulloblastomas, } 2 \text { ependymomas, and } \\
1 \text { pineoblastoma }\end{array}$ & $\begin{array}{l}1 \text { detected at the time of pin placement } \\
\text { surgery continued in a horseshoe } \\
\text { headrest, } 3 \text { after clinical deterioration } \\
\text { immediate postoperatively, and } 1 \text { loose } \\
\text { pin and depressed fracture postoperatively }\end{array}$ \\
\hline \multirow[t]{2}{*}{ Serramito-García et al. (2009) ${ }^{[11]}$} & 19/male & Tectal SOL with hydrocephalus & $48 \mathrm{~h}$ after surgery \\
\hline & & Third ventriculostomy was performed & \\
\hline Jha et al. $(2009)^{[8]}$ & 22/male & Fourth ventricular tumor with hydrocephalus & Intraoperatively \\
\hline Lee and Lin $(2010)^{[6] \#}$ & 38/female & Cervical spine foraminotomy and fixation & 2 days after surgery \\
\hline \multirow[t]{2}{*}{ Naik et al. $(2011)^{[4] \star}$} & 40/female & $\begin{array}{l}\text { Right vestibular schwannoma with } \\
\text { shunted hydrocephalus }\end{array}$ & Immediate postoperatively \\
\hline & & Bilateral extradural hematoma & \\
\hline \multirow[t]{2}{*}{ Won et al. $(2012)^{[13]}$} & $61 /$ female & Right putaminal hemorrhage & Second day after surgery \\
\hline & & Stereotactic aspiration done & \\
\hline Poli et al. $(2013)^{[7]}$ & 7/male & Left cerebellar pilocytic astrocytoma & Immediate postoperatively \\
\hline Chen et al. $(2014)^{[3]}$ & 6/female & Posterior fossa tumor with hydrocephalus & Immediate postoperatively \\
\hline Present case & 12/female & $\begin{array}{l}\text { Fourth ventricular pilocytic astrocytoma } \\
\text { with hydrocephalus }\end{array}$ & Immediate postoperatively \\
\hline
\end{tabular}

\#A case of cervical spine fixation, *A case of bilateral extradural hematoma. NA: Not available, SOL: Space occupying lesion

\section{Financial support and sponsorship}

Nil.

\section{Conflicts of interest}

There are no conflicts of interest.

\section{References}

1. Lee M, Rezai AR, Chou J. Depressed skull fractures in children secondary to skull clamp fixation devices. Pediatr Neurosurg 1994;21:174-7.

2. Vitali AM, Steinbok P. Depressed skull fracture and epidural hematoma from head fixation with pins for craniotomy in children. Childs Nerv Syst 2008;24:917-23.

3. Chen TF, Yang SH, Tsai JC. Depressed skull fracture and epidural hematoma resulted from pin-type head holder for craniotomy in children. J Med Sci 2014;34:238-40.

4. Naik V, Goyal N, Agrawal D. Pin site bilateral epidural hematoma - A rare complication of using Mayfield clamp in neurosurgery. Neurol India 2011;59:649-51.

5. Sade B, Mohr G. Depressed skull fracture and epidural haematoma: An unusual post-operative complication of pin headrest in an adult. Acta Neurochir (Wien) 2005;147:101-3.

6. Lee MJ, Lin EL. The use of the three-pronged Mayfield head clamp resulting in an intracranial epidural hematoma in an adult patient. Eur Spine J 2010;19 Suppl 2:S187-9.

7. Poli JC, Zoia C, Lattanzi D, Balbi S. Epidural haematoma by Mayfield head-holder: Case report and review of literature. J Pediatr Sci 2013;5:e195.

8. Jha NK, Ebrahim S, Fallah A, Cenic A, De Villiers RA. Pin-site epidural hematoma in an adult case of chronic hydrocephalus with associated thinning of the cranium. Br J Neurosurg 2009;23:211-2.

9. Yan HJ. Epidural hematoma following use of a three-point skull clamp. J Clin Neurosci 2007;14:691-3.

10. Tang CT, Hseih CT, Chiang YH, Su YH. Epidural hematoma and depressed skull fracture resulted from pin headrest - A rare complication: Case report. Cesk Slov Neurol N 2007;103:584-6.

11. Serramito-García R, Arcos-Algaba A, Santín-Amo JM, García-Allut A, Bandín-Diéguez FJ, Gelabert-González M. Epidural haematoma due to an headrest in an adult. Neurocirugia (Astur) 2009;20:567-70.

12. Erbayraktar S, Gökmen N, Acar U. Intracranial penetrating injury associated with an intraoperative epidural haematoma caused by a spring-laden pin of a multipoise headrest. Br J Neurosurg 2001;15:425-8.

13. Won YD, Kim CH, Cheong JH, Kim JM. Skull perforation and depressed fracture following skull fixation for stereotactic surgery. Korean J Neurotrauma 2012;8:48-50.

14. Medina M, Melcarne A, Musso C, Ettorre F. Acute brain swelling during removal of supratentorial cystic lesion caused by contralateral extradural hematoma: Case report. Surg Neurol 1997;47:428-31.

15. Berry C, Sandberg DI, Hoh DJ, Krieger MD, McComb JG. Use of cranial fixation pins in pediatric neurosurgery. Neurosurgery 2008;62:913-8. 